\title{
Party government and policy responsiveness. Evidence from three parliamentary democracies
}

\author{
Dimiter Toshkov $^{1 \star}$, Lars Mäder ${ }^{2}$ and Anne Rasmussen ${ }^{1,2}$ \\ ${ }^{1}$ Institute of Public Administration, Leiden University, The Netherlands ${ }^{2}$ Department of Political \\ Science, University of Copenhagen, Denmark \\ ${ }^{\star}$ Corresponding author. Email: d.d.toshkov@fgga.leidenuniv.nl
}

(Received 12 April 2017; revised 28 September 2018; accepted 6 October 2018; first published online 19 November 2018)

\begin{abstract}
Does party government moderate the responsiveness of public policy to public opinion? Analysing a new dataset, we examine whether the ability of governments to respond to the public on 306 specific policy issues in Denmark, Germany and the UK is affected by the extent of coalition conflict and by the fit of the considered policy changes with the government preferences. We find a systematic but relatively weak positive impact of public support on the likelihood and speed of policy change. Contrary to expectations, a higher number of coalition partners are not associated with fewer policy changes nor with weaker responsiveness to public opinion. We also find no evidence that responsiveness to public opinion is necessarily weaker for policy changes that go against the preferences of the government. Rather, it appears that public and government support for policy change are substitute resources.
\end{abstract}

\begin{abstract}
Keywords coalition government; legislative decisionmaking; party government; policy change; policy responsiveness; political parties; public opinion
\end{abstract}

\section{Introduction}

In democracies, public policy should reflect the wishes of the people. In representative democracies embodied in parliamentary political systems, however, public policy is made not directly by the people but by elected representatives in legislative assemblies and cabinet governments. This raises the important question of how public opinion and the preferences of political parties in government interact in affecting policy making.

Research on policy representation (for recent reviews, see Shapiro 2011; Erikson 2015; Wlezien and Soroka 2016) has established that both in the United States (US) and in Europe public opinion has a strong but far from deterministic influence on public policy (see also Page and Shapiro 1983; Monroe 1998; Rasmussen et al. 2018a). This influence is manifested in relatively high degrees of congruence between what the median citizen wants and what the state of policy is (Lax and Phillips 2012), as well as in dynamic responsiveness, in which the state of public policy (e.g. Wlezien 1995; Erikson et al. 2002) and policy agendas (Jennings and 
John 2009; Bevan and Jennings 2014; Alexandrova et al. 2016, Bevan and Rasmussen 2017$)^{1}$ adapt to shifts in public preferences.

The literature on party government has examined the impact of party preferences on aggregate measures of the policy output of governments, finding only scant and contested evidence for the effects of party positions (i.a. Imbeau et al. 2001). Researchers have also investigated how the scope of differences in preferences between the relevant decision-making actors in the political system (Tsebelis 2002; Strøm et al. 2010; Martin and Vanberg 2011) affect legislative production and policy output, and have found mostly negative effects (Tsebelis 1999; Saeki 2009; Schermann and Ennser-Jedenastik 2014; Bräuninger et al. 2015). Yet, very few studies of the policy effects of government preferences, coalition conflict and related concepts, such as veto players and preference heterogeneity, take into account the possible influence of public opinion (but see Binder 1999; Coleman 1999; Toshkov 2011).

In this article, we focus on the question how public opinion and patterns of party government interact in shaping policy making in European parliamentary democracies. We propose a set of hypotheses about the direct effects of public opinion and government preferences on the likelihood of policy change, as well as about the interactions between public opinion, on the one hand, and government preferences, the number of parties in government, and issue salience, on the other.

To test these hypotheses, we employ a comparative design in which we track a total of 306 policy issues across three countries: Denmark, Germany and the UK. For each of these issues, we identify measures of public opinion from representative national public opinion polls, and we trace whether policy change on the issue occurred within a four-year period starting at the time of the opinion poll. We construct measures of the positions of the government parties and we estimate the salience of policy issues using media data. We model two central aspects of policy making - the occurrence of policy change (cf. Gilens 2012), discussed in the main text of the article, and the time it takes for change to occur, discussed in the Supplementary Material (Section 7).

Analysing these data, we find that public support increases the likelihood of policy change and decreases the time until change is adopted. Yet, whereas these effects are systematic, they are relatively small in substantive terms. Despite the concern that coalition governments may respond less to public opinion, we do not find strong evidence that this factor significantly weakens the opinion-policy linkage. Furthermore, even though we encounter some support for a positive effect of government support for a policy change on the likelihood of the change being adopted, there is no evidence that lack of support for a policy by a government decreases significantly responsiveness to public opinion.

These findings are important for understanding the role of party government in parliamentary systems in the process of representation. In empirical terms, we

\footnotetext{
${ }^{1}$ Examining why governments emphasize some issues over others, Bertelli and John (2013) have recently expanded upon the agenda responsiveness literature. Rather than simply argue that governmental agendas directly respond to public priorities, they examine whether returns, risk profiles and uncertainty in public signals about the value of prioritizing policies affect the decisions of politicians how much attention to allocate to a policy domain. Our focus differs from their work as we focus on whether the opinions of citizens are reflected in actual policy outcomes rather than in allocation of attention.
} 
show that the general public can influence policy change to a comparable degree in three political systems that have rather different patterns of party government embedded in different institutions. In theoretical terms, our results help explain why coalition governments might not be less responsive to the wishes of the public. The normative implications of these results are significant as well. First, we show that even if political parties have weakened their links with society (Katz and Mair 1995), when in government they still follow to some extent general public opinion. Second, we find evidence that party opposition cannot always override strong public support for policy change, which is good news for democratic representation.

\section{Public opinion, party government and policy making in parliamentary democracies}

In representative democracies, the influence of public opinion is typically exercised through a process of delegation in which citizens elect representatives who share, express and defend their views, and then the political representatives adopt policies in line with the views that enjoy the support of the citizens. In the particular case of parliamentary democracy, political parties take central place in the process of representation. But how do public opinion and the preferences of political parties in government interact? Before we explore this question empirically, we clarify the theoretical mechanisms involved and introduce a number of hypotheses about this process.

Since in parliamentary democracies, parties typically govern in coalitions, we need to start the theoretical discussion with the problem of preference aggregation. In accordance with the standard postulates of spatial analysis (Shepsle 2010; Tsebelis 2002), we expect that a policy alternative would be adopted if and only if it is preferred to the status quo by the government. When the government is made of a single unified party commanding the necessary majorities in the legislature to pass legislation, this expectation is straightforward. But when governments are composed of (a) multiple parties (i.e. coalition governments) or (b) single but heterogeneous parties with strong factions or (c) single parties or coalitions that do not control majorities in the legislature (i.e. minority governments), we need further assumptions in order to aggregate the preferences of the relevant actors. Below we focus on the case of coalition government, but very similar arguments apply to factions within heterogeneous parties as well; we address minority governments in footnote 9.

There are different assumptions one can make about how the positions of coalition partners combine to form the position of the government. One possible aggregating assumption is that each party in the coalition holds veto power (Tsebelis 2002) over each policy alternative on all issues. This would lead to the expectation that only alternatives that make all government parties better off than the status quo will be adopted (for an illustration, see Figure A1 and the associated discussion in Section 1 of the Supplementary Material).

Alternatively, we can assume that government positions are formed as the weighted average of the positions of the coalition parties, with the weights corresponding to the relative size of the party in the coalition (e.g. Cusack 2001). This assumption agrees with much we know about coalition politics and captures well the intuitions that no coalition partner unilaterally rules in a policy domain, that a 
small coalition party cannot systematically veto alternatives across policy domains, and that bigger partners exercise more influence, yet small ones cannot be ignored.

These assumptions about the way coalitions work are necessary in order to define the proper way for aggregating the positions of governments from the positions of coalition parties. ${ }^{2}$ We report empirical models that are based on both of these assumptions. In the main text, we apply the "weighted average" assumption, whereas we use the "veto power" assumption in the Supplementary Material (see Model A1). In any case, the general expectation remains that the government will only adopt policy alternatives that are closer to its position than the status quo.

This implication is in principle deterministic. However, we need to translate it into a probabilistic expectation in light of the limited data that we have to conduct the empirical tests. ${ }^{3}$ Our data allow us to identify the ordering of the policy alternative and the status quo on the underlying policy scale but not their precise locations. In addition, the measures of party and government positions we have are on a more general scale than the individual policy issues. We assume that the further the government position is to the right (left) on the general scale, the more likely it is that the government will be closer to a policy alternative that moves the policy to the right (left) than to the status quo, and, consequently, the more likely that this policy alternative will be adopted by the government. For example, a government that has a score of 8 on a 1-to-10 economic left-right scale will be more likely to support a policy alternative that reduces the corporate tax rate (hence, moves the status quo in a "right" direction) than a government with a score of 4 . Hence, our first hypothesis is that:

(H1): The further a government position is to the right (left) of a relevant scale, the more likely that the government will adopt a policy alternative moving the status quo to the right (left) on that scale.

Let us turn to the influence of public opinion. So far we have assumed that parties and governments only care about the substance of policies. But in democracies, parties need to consider the popularity of their policy decisions as well. Even if people do not hold strong, well-formed opinions on all policy issues (Achen and Bartels 2016), they might still have reasonably clear relative preferences about the direction and scale of desired policy change (Wlezien 1995). Hence, public support for a particular policy alternative sends a strong signal and can only be ignored at a significant political cost.

Adopting unpopular policies risks that citizens will punish the government parties at the next elections and that the party brand will be damaged. The risk that the public expresses its discontent through protests or civil disobedience should

\footnotetext{
${ }^{2}$ Another possible assumption is that government parties divide the set of policy issues into exclusive spheres of competence so that only one coalition party matters for a particular issue. But this is not very realistic even in systems with strong ministerial autonomy. Major policy changes need to pass through parliament where coalition partners and opposition parties can exercise influence and there are a number of existing institutional mechanisms for controlling coalition partners, such as coalition agreements and the appointment of junior ministers from different parties (Martin and Vanberg 2014).

${ }^{3}$ It has proved, in fact, quite difficult to demonstrate empirically a link between the general positions of parties in government and the content of policy changes they make (cf. the meta-analysis of Imbeau et al. 2001; Schmitt 2016; as well as the more recently, Knill et al. 2010).
} 
also encourage politicians to be attentive to the views of the public (Brooks and Manza 2006). In addition, parties might want to follow the will of the public for normative reasons, i.e. because they believe that public opinion should be respected. Even if the public popularity of policy alternatives is not the only concern of government parties, we would expect, other things being equal, that governments will prefer alternatives with higher public support. In effect, the popularity of different policy alternatives enters the parties' utility functions over different policy alternatives and, combined with the substantive policy implications of these policies, determines the responses of parties to particular alternatives. ${ }^{4}$ (We illustrate how substantive policy preferences and concerns about public opinion interact in Figure A2 in the Supplementary Material).

To the extent that the public popularity of policy alternatives is exogenous to the political process, public opinion provides a soft constraint on the substantive policy choices of parties. Sometimes the substantive benefits of the policy will outweigh the popularity costs for the government, and other times the potential policy gains will not be worth going against public opinion. Similarly, ignoring a policy alternative strongly favoured by the public is costly for the government parties, as they will be seen as unresponsive and undemocratic. This discussion leads to the second hypothesis:

(H2): The stronger the public support for a policy alternative, the higher the likelihood of adopting the policy alternative.

Note that the government will never prefer an alternative that is further away from its substantive position and enjoys lower public support than the status quo. But if either the popularity of the policy alternative increases or the government's substantive preference changes, the government can shift to support the policy alternative. In other words, for policies with weak public support and government support, changing either of these factors matters at the margin. But for policy alternatives that enjoy popular support and are closer to the government's substantive position than the status quo, decreasing either might not have an effect on the government's preference. Even if public support for the policy alternative drops, it might not drop sufficiently to offset proximity on the substantive dimension, and vice versa. Hence, our third hypothesis states that:

(H3): The effect of government support for a policy alternative on the likelihood of its adoption is weaker for policies that enjoy public support. The effect of public support for a policy alternative on the likelihood of its adoption is weaker for policies that enjoy government support.

Expressed in more qualitative terms, this hypothesis implies that the link between (substantive) government positions and policy change should be relatively weak when the public strongly favours a policy alternative, and stronger when there is

\footnotetext{
${ }^{4}$ There are also institutional mechanisms through which parliamentary opposition can bring policy issues to the legislative agenda and entice the government to act. For example, in Germany individual parliamentarians can launch a small inquiry to the government. Five percent of the parliamentarians or one party can start a big inquiry that forces the government to put the item on the agenda. Twenty-five percent of the parliamentarians or, since 2014, the whole opposition, can call an inquiry committee. Lastly, $5 \%$ of the parliamentarians can initiate legislation. Similarly, in Denmark, by getting a resolution adopted, the opposition can commit the Parliament to present a legislative proposal.
} 
lower public support. Similarly, the likelihood of policy change should be more sensitive to the level of public support when there is low government support for the policy change, rather than when the change is strongly favoured by the government already.

In accordance with the mechanisms suggested above, public support should matter more for alternatives that enjoy high salience in society. Salience indicates the importance attached to an issue irrespective of how popular certain policy alternatives are in the population. In work on coalition governance it has, for example, been expected that government parties would prioritise acting on salient issues on which they agree in order to increase their benefits (Martin 2004). When it comes to responding to public opinion, governments should pay more attention to public support on salient issues where their behaviour is more likely to have electoral consequences for them (Lax and Phillips 2012). We can consider salience as increasing the weight of the popularity concerns vis-à-vis the substantive policy concerns of the government. At the limit, on policies that are not salient to the public at all, the popularity of different alternatives should not matter (the weight of this dimension would be zero). Accordingly, we hypothesise that:

(H4): The more salient the policy issue, the stronger the effect of public support for a policy alternative on this issue on the likelihood of its adoption.

So far we considered policy making exclusively through the prism of public and government preferences. But some structural features of governments might have effects on the likelihood of policy change and its responsiveness to public opinion as well. One factor that has been often studied is the influence of coalition conflict (see e.g. Strøm et al. 2010; Martin and Vanberg 2011). This factor refers to the potential for disagreements within the governing coalition that stem from the different preferences of the coalition partners. But if the effect of coalition conflict stems from preference heterogeneity within the coalition (Tsebelis 2002; König et al. 2010; Bräuninger et al. 2015), it is parasitic on the effect of government party preferences, which we already addressed. In addition, in order to relate directly the extent of preference heterogeneity within a coalition to the likelihood of policy change we have to assume that each coalition partner holds veto power over all policy alternatives. We already explained that this is a strong and not very realistic assumption above.

But there might be additional reasons why coalition governments with more diverse partners would be less likely to adopt new policies, on top of what is already captured by the hypothesis about the effect of government party preferences. Coalition governments with more diverse partners might need to spend more time reaching compromises and discovering their common positions (Martin and Vanberg 2004; Konig 2007; Rasmussen and Toshkov 2013), which would limit their overall productiveness. According to Martin and Vanberg $(2004,2005)$, the incentive to scrutinise the coalition partners increases with the ideological divergence within the coalition government, and parliamentary scrutiny also takes time.

The existing literature also suggests another idea, namely that the clarity of responsibility for government (in)actions is diffused, because people find it hard to attribute blame for particular actions to individual coalition parties (Duch et al. 2015). If this is the case, we would expect coalition governments to be less responsive to public opinion, because adopting unpopular policy alternatives will 
not hurt the government parties as much as it would under a single-party government, where it is clear which party goes against the will of the public. Relatedly, Coleman (1999) provides evidence that there is higher responsiveness to public opinion in periods of unified compared to divided government in the US (see also Binder 1999; Gilens 2012). Hence, we hypothesise that:

(H5): The fewer the parties in government, the stronger the effect of public support for a policy alternative on the likelihood of its adoption.

To sum up the theoretical discussion, we expect that the likelihood of adoption of a policy alternative increases with (Hypothesis 1) higher government support and (Hypothesis 2) higher public support for the alternative. In addition, (Hypothesis 3) the effect of government support is weaker for policies that enjoy public support, while (Hypothesis 4) the effect of public support is stronger for more salient issues and (Hypothesis 5) the fewer the number of parties in government.

\section{Research design, data and operationalisation}

In general terms, our research design is based on a comparison of the occurrence of policy change on a large number of policy issues across several national political systems. The countries we study - Denmark, Germany and the UK - are all established parliamentary democracies that differ, however, in their characteristic patterns of party government. While single-party majority cabinets are common in the UK, multiparty coalitions are typical in Germany and in Denmark, where one also observes the phenomenon of multi-party minority coalition cabinets. During the time-period of our analysis, the number of coalition partners differed not only between the three countries but also within the countries over time. For example, the UK experienced both a single-party majority cabinet and a two-party coalition, Germany went through several coalitions that varied in the range of preferences of the participating parties, and Denmark went through a number of successive coalitions, both majority and minority ones.

\section{Unit of observation and sample selection}

Our unit of observation is a policy issue in a country over time, and we analyse 306 issues in the three countries. We look at concrete policy issues, rather than aggregate policy output measures or latent policy dimensions. For each policy issue, we identify public support for a policy alternative (call for public action) that relates to specific measures that the national politicians can adopt. In line with existing research (Gilens 2012; Gilens and Page 2014), we then follow each of these issues from the time of the public opinion poll until the policy change is adopted or, if that does not happen, to a maximum of 48 months. Our focus on concrete issues has the advantage that we relate public opinion and public policy directly (Lax and Phillips 2009; Gilens 2012; Burstein 2014). By selecting a time window of up to four years, we allow ample time for new alternatives to enter the legislative agenda and get adopted. ${ }^{5}$

\footnotetext{
${ }^{5}$ Since the beginning of the observation period for the cases does not coincide with the beginning of the government term (for reasons of availability of public opinion data) following the issues until the end of the term would have provided too little time for governments to respond to many of the issues in our dataset.
} 
To select the policy issues we analyse, we started with identifying relevant questions asked in representative nationwide public opinion surveys in Denmark (1998-2010), Germany (1998-2010) and the UK (2001-2010). To be relevant, the questions had to tap into the attitudes of the adult population towards issues of public policy, to involve a call for future political action, and to relate to specific policy issues. In addition, the questions had to concern issues of national (as opposed to EU and regional/local) policy competences, and the responses had to be measured on a scale on which respondents expressed the extent to which they agreed or not with a given policy change.

We identified a total of 102 survey questions that fulfilled these criteria in Germany, 211 in Denmark, and 239 in the UK. ${ }^{6}$ In our final sample, we took all the 102 relevant questions in Germany and we used random sampling stratified by year to select 102 questions from Denmark and the UK each, for a total of 306 cases. $^{7}$

In all three countries, the selected survey questions cover a wide range of different policy issues and relate to different policy areas that represent diverse policy types: regulatory, (re)distributive and constituent policies (see Table A1 in the Supplementary Material). For instance, in the UK the sample includes questions concerning a possible amnesty to illegal immigrants, the introduction of an identity card system, and the replacement of university tuition fees with a graduate tax scheme.

Our sampling strategy is constrained by the availability of reliable public opinion data representative at the national level (Monroe 1998; Gilens 2012). As a consequence, our sample might be biased towards more salient issues that are more likely to get the attention of polling companies. The potential bias is not necessarily a problem since focusing on questions that have at least some amount of salience makes it "plausible that average citizens may have real opinions and may exert some political influence" (Gilens and Page 2014: 568). Still, it is worth reminding that our sample of issues might not be representative of the universe of all possible policy issues of national competence that could have been on the agenda, despite the fact that it covers a broad range of policies in terms of type and domain.

A recent US study on responsiveness addresses this challenge by sampling its cases from alternatives on the legislative agenda rather than from available polls (Burstein 2014). However, constructing such a potential universe of issues is difficult in the context of a crosscountry comparative study like ours, given that there is no comparative sampling frame of all possible issues that would be applicable to all three countries. Moreover, relying on national legislative databases or media in the three countries would only yield information about issues that have passed a first "threshold of access" by being picked up by either politicians or the media, which might create another source of bias. Instead, only 51 of the 306 issues in our sample were related to an existing bill alternative or cabinet decision when the opinion question was asked, and the sample covers issues of rather different

\footnotetext{
${ }^{6}$ In Denmark, all selected survey questions came from surveys conducted by the Gallup Institute. In Germany, we relied on questions asked by the Politbarometer surveys. For the UK, we relied on a list of questions from YouGov and ICM sampled by Will Jennings, which was further appended by additional survey questions from the mentioned companies.

${ }^{7}$ The sampling was necessitated by the high costs of data collection per policy issue and to a lesser extent by the need to keep the number of cases balanced across the three countries.
} 
salience within each of the three countries (with some issues not receiving any coverage in our newspapers at all). In sum, we can be confident that the sample includes issues of varying media salience and at various stages in the policy-making process.

\section{Outcome variables}

In the empirical analyses reported in the main text, we use logistic regression to model the likelihood of policy change (i.e. whether the national government or parliament adopted primary or secondary legislation in line with the public call for change), for each government that was in office within the four-year observation period that we follow. In the Supplementary Material, we also report the results of analyses of the speed of policy change, as a second theoretically relevant aspect of public policy making. This set of analyses focuses on the duration between the date of the public opinion survey and the date of the policy change, if it occurred within the four-year case-specific period of observation. To detect the occurrence and timing of policy change, we relied on historic information provided by legislative databases, other government (web)sources, online newspaper archives and information provided by interest groups and professional associations. Descriptive statistics of the variables used in the analysis are reported in the Supplementary Material (Table A1).

\section{Explanatory variables}

We operationalise public support for policy change as the percentage of all respondents in favour of the call for policy action as expressed in the public opinion survey. To further explore the possible effect of public opinion, we employ an alternative operationalisation - public support calculated as the share of respondents in favour from those with an opinion; hence, excluding no responses and "don't knows" (see Model A3 in the Supplementary Material).

The measure of government support for policy change requires that we obtain estimates of relevant government and party positions. To do that, we use the Chapel Hill expert survey of party positions (Bakker et al. 2015). ${ }^{8}$ We make the measures policy scale-specific: first we classify each of the 306 policy issues to one of the three main scales in the Chapel Hill dataset - general left/right, economic left/right and GAL-TAN (green, alternative, and liberal versus traditional, authoritarian and nationalist), then we identify the relevant party positions on these scales and assign them to the case, and finally we compute the government support measures. ${ }^{9}$

\footnotetext{
${ }^{8}$ We considered the Manifestos Project data (Klingemann et al. 2007) as an alternative source of party and government positions. We obtained the necessary data and constructed measures on 12 point scales constructed from the Manifesto items related to our policy issues, using the scaling approach suggested by Lowe et al. (2011). The data, however, failed face validity checks as it provided implausible estimates of party positions and relative rankings of the parties on scales and positions. It also provided a worse match with the set of directly-measured party positions we obtained for the German subsample of our data (see Section 2 of the Supplementary Material). Hence, we decided against reporting results based on this data source, which is more appropriate for measuring party attention to particular issues rather than positions as such.

${ }^{9}$ The Danish case presents a theoretical challenge for the measurement of average government positions and coalition conflict because of the minority status of the cabinets in the country during our period of
} 
Matching public opinion data on concrete policy alternatives with government preference data that is on more general policy scales is less than ideal, especially since the policy status quo points cannot be located on the general policy scales.

To address this concern and explore the validity of the policy scale measures, we obtained direct measures of party support or opposition to the subset of 102 cases in Germany (Romeijn 2018). The direct measures were based on hand-coding of the party positions on the basis of statements in the national media. Comparing the two sets of measures, we found that the general policy scale measures are strongly and significantly predictive of party support/opposition on the concrete policy issues. Moreover, when we dichotomised the party positions on the general policy scales at the mid-points, we found that in close to two-thirds of the cases there was agreement between the two sets of measures (i.e. when the party position was to the right of the mid-point of the scale, the direct measure indicated party opposition to a policy alternative that was moving the status quo to the left). These results indicate that the expert survey-based estimates of party positions are imperfect but altogether informative.

We conducted similar tests comparing the party positions on the specific issues to scores obtained from the Manifesto project scores, assigning each issue to one of twelve scales (Klingemann et al. 2007; Lowe et al. 2011). Despite the higher number of scales in the Manifesto dataset, we obtain a weaker match with the directly measured party positions than with the Chapel Hill expert data. The details of the validation tests are provided in Section 3 of the Supplementary Material. To check to what extent the results of our empirical analyses are dependent on the exact measure of government preferences used, our analysis replicates the analysis using the Chapel Hills data with the direct hand-coded measure of government support for the German sample where we have both measures available (see below).

As mentioned, we employ two ways to aggregate government positions from party positions, consistent with the different theoretical assumptions about coalition politics we discuss in the theory section. The first set of measures are operationalised as the weighted average of the positions of the parties in government, with the weights corresponding to the relative shares of the seats in the legislature held by the coalition party from the total number of seats held in the legislature by all coalition partners. ${ }^{10}$ To obtain a measure of relative government support for policy change from absolute government positions, we have to consider the direction of policy change for each case. To that end, we first code the implied direction of each policy change (e.g. left or right), and then we invert the original

observation. Taking into account only the parties that are formally part of the (minority) coalition might underestimate the degree of intra-government conflict and misrepresent the average government position since the governing parties need the support of additional parties in the legislature to pass legislation. At the same time, minority coalitions have flexibility in choosing a partner in the legislature for particular policy alternatives that is not easily captured. Nevertheless, we constructed alternative measures of government positions and coalition conflict in Denmark that take into account the unofficial but regular legislative partners of the parties in the governing minority coalitions. The results based on these alternative measures can be found in Table A2 in the Supplementary Material. The results are very similar to the ones that do not take into account the minority status, and the effects of government positions and number of parties in government are, if anything, weaker.

${ }^{10}$ For easier interpretation, the original scales, which range from 1 to 10 , are centred at 0 . 
government positions where needed, so that more right wing parties are aligned with right-leaning policy changes and left wing parties with left-leaning changes. ${ }^{11}$

For the second, alternative, way of aggregating party preferences into government preferences, we consider each government party as a veto player. Accordingly, we take the position of the left-most government party as the government position for changes in a right-leaning direction, and the position of the right-most government party for changes in a left-leaning direction ${ }^{12}$ (see Model A1).

We measure the media saliency of each case by tracking the number of newspaper articles related to the case in one major national newspaper in each country (Politiken in Denmark, Sueddeutsche Zeitung in Germany and The Guardian in the UK) in the period between one month prior and one month after the public opinion survey was conducted. ${ }^{13}$

In addition to these main variables of interest, we include a variable that indicates whether the call for public action was related to an existing bill or cabinet decision when the public opinion question was asked, because such cases could have a higher likelihood of policy change. Also, all empirical models reported below include country fixed effects (dummies) in order to control for unobserved country-level heterogeneity in the likelihood of occurrence of policy change. Because in the logistic regression models the unit of analysis is a government spell (a period of time during which a government is responsible for a policy issue), we also include as a control the remaining formal tenure of the government (in months) from the moment of its inauguration or the date of the public opinion survey (whichever comes last) to the moment of its expected dissolution or the end of our observation period (whichever comes first).

\section{Empirical analyses}

\section{Public opinion and policy change}

We present a detailed analysis of the bivariate relationship between public opinion and policy change in the Supplementary Material (Section 4 with Figures A3 and A4). In summary, in all three countries the likelihood of policy change increases with higher levels of public support, both absolute and net. In substantive terms,

\footnotetext{
${ }^{11}$ For example, if the call for action concerned increasing taxation (left-leaning policy change), we inverted the position scores of the relevant government, so that higher scores would be associated with more economically left-wing positions (on the original scales, higher scores are associated with more right/ TAN positions).

${ }^{12}$ When measuring the positions of the government parties in Germany, we only focus on the parties' seats in the lower Bundestag. In principle, the Bundesrat (upper chamber) has the potential to influence some legislative acts. However, a large share of legislative act do not require the vote of the upper chamber, and the government can find creative ways to circumvent a potential veto by the Bundesrat (see Merkel 2003).

${ }^{13}$ The Boolean media keyword search was conducted using the FACTIVA database. A complete list, including all Boolean search requests, for all the 306 survey questions will be provided by the authors on request. The keywords represent the respective items as accurately as possible while paying attention to the scope of the policy item. We included the plurals of the selected key words, their word stems, and their synonyms. The media count for each country is standardised, i.e. the variable is rescaled to have a mean of zero and a standard deviation of one in each country. By measuring issue coverage within a fixed two month period, we avoid bias resulting from the fact that opinion items which experience a policy change receive higher media attention in the time period before the actual policy change occurs.
} 
however, the effect of public opinion is relatively small. We also observe rather modest levels of congruence between policy and majority public opinion at the beginning of the observation period, and even more modest levels of improvements in congruence over time, despite a considerable degree of policy-making activity. ${ }^{14}$

\section{Multivariate logistic regression models}

Table 1 presents the results of our multivariate logistic regression models of the likelihood of policy change, for each government that was in office within the fouryear observation period, using the Chapel Hill measures of party positions. Model 1 includes the main variables of interest and the controls, but no interactions. Model 2 adds the interaction between government support and public support. Model 3 includes an interaction between the number of parties in government and

Table 1. Logistic regression models of policy change

\begin{tabular}{|c|c|c|c|c|}
\hline & Model 1 & Model 2 & Model 3 & Model 4 \\
\hline \multirow[t]{2}{*}{ Intercept } & $-2.22(0.81)$ & $-2.19(0.81)$ & $-2.30(0.81)$ & $-2.20(0.81)$ \\
\hline & $p$-value $=0.006$ & $p$-value $=0.007$ & $p$-value $=0.005$ & $p$-value $=0.006$ \\
\hline \multirow[t]{2}{*}{ Public support } & $1.41(0.56)$ & $1.48(0.57)$ & $3.53(1.90)$ & $1.13(0.87)$ \\
\hline & $p$-value $=0.011$ & $p$-value $=0.009$ & $p$-value $=0.063$ & $p$-value $=0.193$ \\
\hline \multirow[t]{2}{*}{ Government support } & $0.12(0.08)$ & $0.14(0.09)$ & $0.12(0.08)$ & $0.12(0.08)$ \\
\hline & $p$-value $=0.143$ & $p$-value $=0.104$ & $p$-value $=0.162$ & $p$-value $=0.145$ \\
\hline $\begin{array}{l}\text { Public support } \times \\
\text { government support }\end{array}$ & / & $\begin{array}{c}-0.46(0.41) \\
p \text {-value }=0.26\end{array}$ & l & / \\
\hline \multirow{2}{*}{$\begin{array}{l}\text { Number of parties in } \\
\text { government }\end{array}$} & $-0.32(0.26)$ & $-0.34(0.26)$ & $-0.29(0.26)$ & $-0.33(0.26)$ \\
\hline & $p$-value $=0.213$ & $p$-value $=0.198$ & $p$-value $=0.271$ & $p$-value $=0.208$ \\
\hline $\begin{array}{l}\text { Public support } \times \\
\text { number of parties }\end{array}$ & / & / & $\begin{array}{c}-0.98(0.84) \\
p \text {-value }=0.241\end{array}$ & / \\
\hline \multirow[t]{2}{*}{ Media salience } & $0.31(0.10)$ & $0.31(0.10)$ & $0.32(0.1)$ & $0.31(0.10)$ \\
\hline & $p$-value $=0.002$ & $p$-value $=0.002$ & $p$-value $=0.002$ & $p$-value $=0.003$ \\
\hline \multirow{2}{*}{$\begin{array}{l}\text { Public support } \times \\
\text { media }\end{array}$} & / & / & / & $0.18(0.42)$ \\
\hline & & & & $p$-value $=0.673$ \\
\hline \multirow[t]{2}{*}{ Existing proposal } & $0.91(0.29)$ & $0.91(0.29)$ & $0.91(0.29)$ & $0.91(0.29)$ \\
\hline & $p$-value $=0.002$ & $p$-value $=0.002$ & $p$-value $=0.002$ & $p$-value $=0.002$ \\
\hline \multirow[t]{2}{*}{ Remaining months } & $0.04(0.01)$ & $0.04(0.01)$ & $0.04(0.01)$ & $0.04(0.01)$ \\
\hline & $\mathrm{p}$-value $<0.001$ & p-value $<0.001$ & $\mathrm{p}$-value $<0.001$ & $\mathrm{p}$-value $<0.001$ \\
\hline \multirow[t]{2}{*}{ Denmark } & $0.26(0.32)$ & $0.23(0.33)$ & $0.28(0.32)$ & $0.26(0.32)$ \\
\hline & $p$-value $=0.418$ & $p$-value $=0.486$ & $p$-value $=0.380$ & $p$-value $=0.427$ \\
\hline \multirow[t]{2}{*}{ UK } & $-1.28(0.45)$ & $-1.29(0.45)$ & $-1.30(0.46)$ & $-1.29(0.45)$ \\
\hline & $p$-value $=0.005$ & $p$-value $=0.004$ & $p$-value $=0.004$ & $p$-value $=0.004$ \\
\hline AIC & 515 & 516 & 516 & 517 \\
\hline
\end{tabular}

Note: Logistic regression models (with logit link). Dependent variable: occurrence of policy change. Unit of analysis is a government spell on a policy issue; $N=525$. Unstandardised and unexponentiated coefficients. Public opinion centred at 0.5. Media salience is logged.

\footnotetext{
${ }^{14} \mathrm{We}$ should note that the positive effect of public opinion on the likelihood on policy change does not appear to be linear, but the exact form of the relationship differs across the three countries and does not follow a simple interpretable pattern (for details, see Figure A4 in the Supplementary Material). The nonlinearity is less pronounced in a multivariate setting, however.
} 
public support, while Model 4 includes an interaction between media salience and public support. $^{15}$

We see that government support for the policy alternative has the positive effect suggested in hypothesis 1 . The estimate of the effect, however, lacks the necessary precision to attain standard levels of statistical significance, with the p-value varying between 0.10 and 0.16 in the four models. In contrast, the effect of public support is statistically significant at the 95\% confidence level in Models 1 and 2 and is consistently positive, in line with the expectation in hypothesis 2 . Yet, in substantive terms the effect is relatively small: for an increase of public support for a policy from 50 to $60 \%$, the coefficients from Model 1 imply that the likelihood of policy change increases with 2.1 percentage points (other covariates held constant at their means or typical values).

Looking in more detail at the patterns in the data (see also Figure A3 in the Supplementary Material), we note that in Germany, despite a considerable amount of policy activity, the probability of policy change was not strongly affected by the degree of public support and, as a result, overall congruence between the wishes of the majority and the state of policy hardly improved over a four-year observation period.

Responsiveness was higher in the case of the UK, but coupled with a rather stronger status quo bias of the British policy-making system, this also did not produce a high degree of congruence between policy and majority public opinion. In Denmark, moderate responsiveness and relatively high degree of policy-making activity produced the highest degrees of congruence we observed, although in absolute terms congruence was still disappointingly low.

According to Model 2, the interaction between public and government support is negative, although nonsignificant at the $95 \%$ level. When we plot the interaction, we can see that the sensitivity of the likelihood of policy change to the level of public support is stronger for policy changes that lack government support and is rather flat for policies that enjoy government support. Similarly, the effect of government support on the likelihood of policy change is rather steep for policy changes that lack public support, but nonexistent for polices that enjoy public support (Figure A5 illustrating these effects is to be found in the Supplementary Material). These inferences are consistent with the theoretical predictions put forward in Hypothesis 3. Yet, in light of the lack of precision with which the effects are estimated, we should remain cautious in the interpretation. We can say that there is no evidence in our data that policy responsiveness to public opinion is less likely on policy issues that would move policy in a direction opposite to the government positions. If anything, public support for a policy seems to matter more when the policy changes are not in line with the preferences of the government. If we take the results of Model 2 and Figure A5 seriously despite the lack of standard levels of statistical significance, it would appear that a policy change has a very similar chance of being adopted (a) under a supportive government irrespective of its level of public support and (b) under an opposing government but only if it enjoys very high levels of public support.

Media salience has a strong and significant positive effect on the likelihood of policy adoption: doubling the number of newspaper articles on a topic (salience) is

\footnotetext{
${ }^{15}$ The interactions are entered separately to ease interpretation of the marginal effects. A model including all interactions at the same time is reported in the Supplementary Material (Model A4).
} 
associated with a $40 \%$ higher risk of policy change. Against the expectation in Hypothesis 4, there is no evidence, however, for an interaction with public opinion (Model 4; for the plot, see Figure A7 in the Supplementary Material). This is important in light of our hypothesis and the existing literature that has emphasised the potential role of salience in moderating the impact of public opinion on policy change.

The effect of the number of parties in government is negative, but, again, the effect is not estimated precisely enough to reach statistical significance at the $95 \%$ level. The effect is stronger within countries but disappears in the pooled data. Examining the interaction effect between the number of parties in government and public opinion (Model 3), we find the negative sign that we hypothesised in Hypothesis 4, but the standard error of the estimate of the coefficient is rather large, so that statistical significance is not attained. Looking at the figure plotting the interaction effect (Figure A6 in the Supplementary Material), confirms the impression that the size of the interaction effect is large in substantive terms, but there is considerable uncertainty about the estimates. ${ }^{16}$

Examining the data in more detail, it is remarkable that Denmark - governed by minority coalitions throughout our study period - exhibited the highest ability to produce policy change, while the UK - governed for a large part of the observation period by a single party majority government - experience the least amount of policy change.

Finally, we should note that the control variables have the expected effects in Models 1-4: the formal time of a government remaining in office and the prior existence of a government bill all increase the likelihood of policy change. The existence of a bill makes it more than 2.5 more likely that policy change will follow, and each additional month in office adds approximately a $4 \%$ increase in the odds.

\section{Using the direct measures of government support}

The models reported in Table 1 are based on the general policy scale-based measures of government positions. As discussed above, for the German subset of the data we also have direct measures of party and government support or opposition to the policy alternatives.

To explore the extent to which the empirical results are sensitive to the type of government position measures used, we replicate two of the models using the direct measures, and report the results in Table 2. According to these models, the effect of government support, when measured directly, is stronger and is estimated more precisely (the p-values of the coefficients of government support are much lower despite the lower number of observations compared to the models in Table 1).

Moreover, the effect of public support is now weaker (although still positive), which accords with the idea that, when measured directly, explicit party support for policy alternatives already captures concerns about the public popularity of policies in addition to the substantive policy preferences of the parties. It is also worth noting that the effect of the variable capturing whether the issue was already

\footnotetext{
${ }^{16}$ When we use the alternative operationalisations of the number of parties in government and government support that take into account the unofficial partners of the governing parties in the Danish minority cabinets, we obtain essentially the same results.
} 
Table 2. Logistic regression models of policy change in Germany

\begin{tabular}{|c|c|c|}
\hline & Model 5 & Model 6 \\
\hline \multirow[t]{2}{*}{ Intercept } & $-4.82(1.62)$ & $-4.77(1.63)$ \\
\hline & $p$-value $=0.003$ & $p$-value $=0.003$ \\
\hline \multirow[t]{2}{*}{ Public support } & $0.21(1.00)$ & $0.44(1.09)$ \\
\hline & $p$-value $=0.830$ & $p$-value $=0.690$ \\
\hline \multirow[t]{2}{*}{ Government support } & $1.37(0.34)$ & $1.35(0.34)$ \\
\hline & p-value $<0.001$ & $p$-value $<0.001$ \\
\hline \multirow[t]{2}{*}{ Public support $\times$ government support } & / & $-0.76(1.39)$ \\
\hline & & $p$-value $=0.585$ \\
\hline \multirow[t]{2}{*}{ Number of parties in government } & $0.61(0.45)$ & $0.60(0.45)$ \\
\hline & $p$-value $=0.174$ & $p$-value $=0.182$ \\
\hline \multirow[t]{2}{*}{ Media salience } & $0.46(0.20)$ & $0.46(0.20)$ \\
\hline & $p$-value $=0.023$ & $p$-value $=0.023$ \\
\hline \multirow[t]{2}{*}{ Existing proposal } & $0.75(0.61)$ & $0.72(0.61)$ \\
\hline & $p$-value $=0.213$ & $p$-value $=0.233$ \\
\hline \multirow[t]{2}{*}{ Remaining months } & $0.02(0.02)$ & $0.02(0.02)$ \\
\hline & $p$-value $=0.145$ & $p$-value $=0.166$ \\
\hline $\mathrm{AIC}$ & 168 & 170 \\
\hline
\end{tabular}

Note: Logistic regression models (with logit link). Dependent variable: occurrence of policy change. Unit of analysis is a government spell on a policy issue; $N=159$. Unstandardised and unexponentiated coefficients. Public opinion centred at 0.5. Media salience is logged.

subject to an existing legislative proposal (bill) is no longer significant, unlike the equivalent models in Table 1 . As in Model 2 in Table 1, the interaction effect between public support and government support is negative (see Model 6 in Table 2), but is not statistically significant.

\section{Different ways of aggregating party positions into government positions}

In the previous sections, we discussed the different ways in which one can aggregate the positions of parties ruling as a coalition into a single government position. The models reported in Tables 1 and 2 are based on the "weighted average" assumption in which each party has influence proportional to the share of seats in the legislature it holds relative to the other coalition partners. As mentioned, a prominent alternative assumption is that each coalition partner holds veto power over all policy issues. When we aggregate government position using this "veto power" assumption, we obtain similar results to the ones reported in Table 1, but the positive effect of government positions is somewhat weaker and less precisely estimated (see Model A1 in the Supplementary Material). The pattern is similar when we compare the two methods of aggregating the direct measures of party support/opposition: the effects based on the "weighted average" assumption are stronger and more precisely estimated than the ones based on the "veto power" assumption. This suggests that the weighted average assumption is a better model of how party positions are aggregated within governments, at least when as broad a range of policies as the one in our sample is considered.

\section{Conclusion}

Recent years have witnessed an expansion of the study of responsiveness to a broad range of political systems, and a new research agenda has started exploring how 
contextual differences in institutional architectures might contribute to explaining varying degrees of opinion-policy linkage (Lax and Phillips 2012; Wlezien and Soroka 2012; Rasmussen et al. 2018a). At the same time, other contextual factors that may affect responsiveness, such as the impact of party positions and coalition government have received less attention. By linking insights from the literatures on policy responsiveness and party government, we identified a number of hypotheses regarding about how government positions, the number of parties in government, and salience could not only impact policy making directly, but also moderate the degree of policy responsiveness.

Testing these hypotheses, we found a systematic but limited degree of policy responsiveness in the three parliamentary political systems examined. Interestingly, we did not find that responsiveness is too constrained when the policy alternatives on the agenda run counter to the general policy positions of the parties. To put it differently, responsiveness was not weaker on issues that would move policy in the opposite direction to the policy preferences of the government, as inferred from their positions on general left-right scales. If anything, it would appear that government and public support are substitutes, so that public support for policy change matters more when the policy does not enjoy government support, and government support for policy change matters more when the policy change is not favoured by the public. Government support, however, when measured directly, was a strong predictor of the likelihood of policy change, at least in the case of Germany, for which such data were available.

In addition, we found only weak evidence that the number of coalition partners has a negative effect on policy adoption or that it moderates policy responsiveness. The lack of a strong effect of coalition conflict on policy-making capacity is unexpected, although in hindsight we can evoke reference to the concept of ministerial autonomy to rationalise the null result (Martin and Vanberg 2014; Laver and Shepsle 1994). Moreover, it needs to be remembered that even if holding governments to account may be more difficult in countries with frequent coalition governments, coalition governance does not only make it harder for governments to act on popular policies, but may also prevent them from adopting unpopular ones in practice (Gilens 2012).

These results are important because they imply that different political systems with different patterns of party government can achieve comparable levels of responsiveness. The data also suggest that parties, when in government, are constrained as to their abilities to ignore public preferences for policy change, even when the change will contradict their general ideological orientations. So even if, in general, parties have weakened their links with society (Katz and Mair 1995), when they have to govern, they still reflect the wishes of the median citizen to a considerable, if imperfect, extent.

Future research should extend our study of responsiveness to other parliamentary systems with strong parties. While it is reassuring to also find the signs of responsiveness in such systems, the complex relationships between coalition status, partisan preferences and responsiveness in these contexts deserve further scrutiny. A promising approach for such research would extend our efforts and expand the limited existing data measuring party preferences related to specific issues. Our study already improves on existing literature by linking public policy, public opinion and government positions on three different scales, rather than simply using general left-right ideological positions as proxies for government preferences. 
But there could be advantages of looking into even more concrete party positions on policy issues in order to disentangle the effects of government preferences on policy changes and responsiveness (cf. Romeijn 2018). It is possible that the stronger effects of government preferences on policy change and on responsiveness can be found with more direct measures of party and government preferences.

There is also scope for extending our research to studies of the dynamic relationship between opinion and policy over time in Western European parliamentary democracies. As mentioned, responsiveness is likely to be a reciprocal relationship, in which both opinion and policy adapt to each other. In a study of a high number of different issues like ours, examining the dynamic relationship is not possible due to the limited availability of repeated opinion polls on the same specific topic in the examined countries. By focusing on specific issues, we address one of the criticisms of studies linking general measures of opinion and policy when it comes to assessing causality. They face the potential challenge that the issues used to construct the aggregate opinion and policy measures may not be the same (Lax and Phillips 2012; Burstein 2014). Instead, our approach gives us confidence that the public has expressed its attitudes towards the same policies as the ones for which we measure policy outcomes. However, future research should complement our research by scrutinising the reciprocal linkage between opinion and policy further in studies of the small subset of specific policy issues for which time series data are available (e.g. Rasmussen et al. 2018b) and by relying on qualitative and experimental methods.

Supplementary materials. To view supplementary material for this article, please visit https://doi.org/ 10.1017/S0143814X18000417

Data Availability Statement. Replication materials are available at https://doi.org/10.7910/DVN/ UI7OFK.

Acknowledgements. Research for this article has been supported by the Danish Council for Independent Research (Sapere Aude Grant 0602-02642B) and the Netherlands Organization for Scientific Research (VIDI Grant 452-12-008). We would like to thank Jeroen Romeijn for access to the GovLis data on the policy positions of German political parties. We would also like to thank Linda Flöthe, Will Jennings, Justin Phillips, Stefanie Reher, James Snyder, the Editor and the reviewers at the Journal of Public Policy for useful comments and suggestions on earlier drafts of this article. We also benefited from comments received at the annual meetings of the European Political Studies Association (2015), the American Political Science Association (2015), the 3rd International Public Policy Conference (2017), and the workshops "Interest Groups and Policy Responsiveness" at the University of Copenhagen (2016) and "The Responsible Party Model in Times of Dealignment" at the University of Leuven (2016). Finally, we are grateful to Benjamin Egerod and Sophia Hunger for the dedicated work they put into data collection for this article.

\section{References}

Achen CH and Bartels LM (2016) Democracy for Realists: Why Elections Do Not Produce Responsive Government. Princeton: Princeton University Press.

Alexandrova P, Rasmussen A and Toshkov D (2016) Agenda Responsiveness in the European Council: Public Priorities, Policy Problems and Political Attention. West European Politics 39(4): 605-627.

Bakker R, de Vries C, Edwards E, Hooghe L, Jolly S, Marks G, Polk J, Rovny J, Steenbergen M and Vachudova MA (2015) Measuring Party Positions in Europe: The Chapel Hill Expert Survey Trend File, 1999-2010. Party Politics 21(1): 143-152.

Bertelli AM and John P (2013) Public Policy Investment: Risk and Return in British Politics. British Journal of Political Science 43(4): 741-773. 
Bevan S and Rasmussen A (2017) When does government listen to the public? Voluntary associations and dynamic agenda representation in the United States. Policy Studies Journal. Online First.

Bevan S and Jennings W (2014) Representation, Agendas and Institutions. European Journal of Political Research 53(1): 37-56.

Binder SA (1999) The Dynamics of Legislative Gridlock, 1947-96. American Political Science Review 93(3): 519-533.

Bräuninger T, Debus M and Wüst F (2015) Governments, Parliaments and Legislative Activity. Political Science Research and Methods 3(1): 1-26.

Brooks C and Manza J (2006) Social policy responsiveness in developed democracies. American Sociological Review 71(3): 474-494.

Burstein P (2014) American Public Opinion, Advocacy and Policy in Congress. Cambridge: Cambridge University Press.

Coleman JJ (1999) Unified Government, Divided Government, and Party Responsiveness. The American Political Science Review 93(4): 821-835.

Cusack TR (2001) Partisanship in the Setting and Coordination of Fiscal and Monetary Policies. European Journal of Political Research 40(1): 93-115.

Duch R, Przepiorka W and Stevenson R (2015) Responsibility Attribution for Collective Decision Makers. American Journal of Political Science 59(2): 372-389.

Erikson RS (2015) Policy Responsiveness to Public Opinion. In Oxford Bibliographies. https://doi.org/ 10.1093/OBO/9780199756223-0103 (accessed 1 June 2018).

Erikson RS, Mackuen MB and Stimson JA (2002) The Macro Polity. Cambridge: Cambridge University Press.

Gilens M (2012) Affluence and Influence: Economic Inequality and Political Power in America. Princeton: Princeton University Press.

Gilens M and Page BI (2014) Testing Theories of American Politics: Elites, Interest Groups, and Average Citizens. Perspectives on Politics 12(3): 564-581.

Imbeau LM, Pétry F and Lamari M (2001) Left-Right Party Ideology and Government Policies: A metaanalysis. European Journal of Political Research 40(1): 1-29.

Jennings W and John P (2009) The Dynamics of Political Attention: Public Opinion and the Queen's Speech in the United Kingdom. American Journal of Political Science 53(4): 838-854.

Katz RS and Mair P (1995) Changing Models of Party Organization and Party Democracy. Party Politics 1(1): 5-28.

Klingemann H-D, Volkens A, Bara J and Budge I (2007) Mapping Policy Preferences II: Estimates for Parties, Electors and Governments in Central and Eastern Europe, European Union and OECD 19902003. Oxford: Oxford University Press.

Knill C, Debus M and Heichel S (2010) Do parties matter in internationalised policy areas? The impact of political parties on environmental policy outputs in 18 OECD countries, 1970-2000. European Journal of Political Research 49(3): 301-336.

Konig T (2007) Divergence or Convergence? From Ever-Growing to Ever-Slowing European Legislative Decision Making. European Journal of Political Research 46(3): 417-444.

König T, Tsebelis G and Debus M (2010) Reform Processes and Policy Change: Veto Players and DecisionMaking in Modern Democracies. Berlin, Germany: Springer Science \& Business Media.

Laver M and Shepsle KA (1994) Cabinet Ministers and Parliamentary Government. Cambridge: Cambridge University Press.

Lax JR and Phillips JH (2009) How Should We Estimate Public Opinion in The States? American Journal of Political Science 53(1): 107-121.

Lax JR and Phillips JH (2012) The Democratic Deficit in the States. American Journal of Political Science 56(1): 148-166.

Lowe W, et al (2011) Scaling Policy Preferences from Coded Political Texts. Legislative Studies Quarterly 36(1): 123-155.

Martin LW (2004) The Government Agenda in Parliamentary Democracies. American Journal of Political Science 48(3): 445-461.

Martin LW and Vanberg G (2004) Policing the Bargain: Coalition Government and Parliamentary Scrutiny. American Journal of Political Science 48(1): 13-27. 
Martin LW and Vanberg G (2011) Parliaments and Coalitions. The Role of Legislative Institutions in Multiparty Governance. New York: Oxford University Press.

Martin LW and Vanberg G (2014) Parties and Policymaking in Multiparty Governments: The Legislative Median, Ministerial Autonomy, and the Coalition Compromise. American Journal of Political Science 58(4): 979-996.

Merkel W (2003) Institutionen und Reformpolitik: Drei Fallstudien zur Vetospieler-Theorie. Berliner Journal für Soziologie 13, 255-274.

Monroe AD (1998) Public Opinion and Public Policy, 1980-1993. The Public Opinion Quarterly 62(1): 6-28.

Page BI and Shapiro RY (1983) Effects of Public-Opinion on Policy. American Political Science Review 77(1): $175-190$.

Rasmussen A and Toshkov D (2013) The Effect of Stakeholder Involvement on Legislative Duration: Consultation of External Actors and Legislative Duration in the European Union. European Union Politics 14(3): 366-387.

Rasmussen A, Reher S and Toshkov D (2018a) The Opinion-Policy Nexus in Europe and the Role of Political Institutions. European Journal of Political Research 56(1): 1-23.

Rasmussen A, Romeijn J and Toshkov D (2018b) Dynamics of Regulatory Policymaking in Sweden: The Role of Media Advocacy and Public Opinion. Scandinavian Political Studies 41(1): 49-74.

Romeijn J (2018) Do Political Parties Listen to the Public? Public Opinion-Party Linkage on Specific Policy Issues. Party Politics, OnlineFirst.

Saeki M (2009) Gridlock in the Government of the United States: Influence of Divided Government and Veto Players. British Journal of Political Science 39(03): 587-607.

Schermann K and Ennser-Jedenastik L (2014) Coalition Policy-Making under Constraints: Examining the Role of Preferences and Institutions. West European Politics 37(3): 564-583.

Schmitt C (2016) Panel data analysis and partisan variables: how periodization does influence partisan effects. Journal of European Public Policy 23(10): 1442-1459.

Shapiro RY (2011) Public Opinion and American Democracy. Public Opinion Quarterly 75(5): 982-1017.

Shepsle K (2010) Analyzing politics: Rationality, behavior, and institutions. New York, NY: W.W. Norton.

Strøm K, Müller WC and Smith DM (2010) Parliamentary Control of Coalition Governments. Annual Review of Political Science 13(1): 517-535.

Toshkov D (2011) Public Opinion and Policy Output in the European Union: A lost Relationship. European Union Politics 12(2): 169-191.

Tsebelis G (1999) Veto Players and Law Production in Parliamentary Democracies: An Empirical Analysis. American Political Science Review 93(3): 591-608.

Tsebelis G (2002) Veto Players: How Political Institutions Work. Princeton: Princeton University Press.

Wlezien C (1995) The Public as Thermostat - Dynamics of Preferences for Spending. American Journal of Political Science 39(4): 981-1000.

Wlezien C and Soroka S (2016) Public Opinion and Public Policy. Oxford Research Encyclopedia. Oxford: Oxford University Press.

Wlezien C and Soroka SN (2012) Political Institutions and the Opinion-Policy Link. West European Politics 35(6): 1407-1432.

Cite this article: Toshkov, D., Mäder, L., Rasmussen, A. 2020. Party government and policy responsiveness. Evidence from three parliamentary democracies. Journal of Public Policy 40: 329-347, doi:10.1017/ S0143814X18000417 